ARTIGO ORIGINAL

\title{
Evolução da técnica de PCR: sua contribuição no diagnóstico da infecção por HPV
}

\author{
Evolution of techinique PCR : its contribution to infection diagnosis by HPV \\ Marta Soraia L. Menêses ${ }^{1}$, Maria Betânia P. Toralles², Carlos Maurício Cardeal Mendes ${ }^{3^{*}}$ \\ ${ }^{1}$ Farmacêutica, especialista em Análises Clínicas, pela Sociedade Brasileira de Citologia Clínica (SBCC); ${ }^{2}$ Doutor \\ em Medicina e Saúde, docente do Programa Processos Interativos dos Órgãos e Sistemas, Universidade Federal \\ da Bahia. ${ }^{3}$ Doutor em Saúde e Epidemiologia, docente do Programa Processos Interativos dos Órgãos e Sistemas, \\ Universidade Federal da Bahia.
}

\begin{abstract}
Resumo
Introdução: a reação em cadeia da polimerase (PCR) é a técnica de biologia molecular mais utilizada na deteç̧ão viral, principalmente em situações onde a quantidade de DNA disponível é pequena. O papilomavírus humano (HPV) representa um dos mais graves problemas de saúde pública e está associado ao câncer do colo do útero, especialmente em países em desenvolvimento, como o Brasil, que desde 2009 já apresentava 40 mil novos casos por ano. Objetivo: descrever a evolução da PCR e sua contribuição no diagnóstico do HPV. Metodologia: realizou-se uma revisão de literatura a partir de publicações disponíveis em base de dados eletrônicos, como Science Direct, SciELO, Pubmed, Instituto Nacional do Câncer e Ministério da Saúde do Brasil, nos últimos cinco anos. Resultados: dentre as técnicas citadas nesta revisão de literatura, todas têm alta relevância na detecção de genotipagem do HPV, embora a escolha quanto ao melhor desempenho fique a critério do pesquisador. A técnica de Nested PCR demonstra ser a mais vantajosa na deteç̧ão do vírus, pelo fato de ter uma maior sensibilidade, em comparação com as demais. Conclusão: a técnica PCR possui alta sensibilidade (90-100\%) e apresenta 92,8 a $100 \%$ de especificidade, sendo padrão ouro para a detecção de DNA do HPV, em amostras citológicas do câncer de colo do útero. Assim, os dados obtidos permitem constatar que a técnica PCR, utilizada para o rastreamento do HPV, é considerada padrão ouro, tendo maior sensibilidade, especificidade e velocidade de análise, devendo ser o método de escolha para o diagnóstico eficiente do HPV.
\end{abstract}

Palavras-chaves: Papiloma vírus humano. HPV. PCR. PCR em tempo real. Câncer uterino. Neoplasia intraepitelial cervical.

\begin{abstract}
Introduction: polymerase chain reaction (PCR) is the most widely used molecular biology technique for viral detection, especially in situations where the amount of available DNA is small. Human papillomavirus (HPV) represents one of the most serious public health problems and is associated with cervical cancer, especially in developing countries such as Brazil that has had 40,000 (forty thousand) new cases a year, since 2009. Objective: to describe the evolution of PCR and its contribution to HPV diagnosis. Methodology: a literature review was conducted from publications available in electronic databases, such as Science Direct, SciELO, Pubmed, National Cancer Institute and Ministry of Health of Brazil, in the last five years. Results: among the techniques cited in this literature review, all have high relevance in the detection of HPV genotyping, although the choice for the best performance is at the discretion of the researcher. The Nested PCR technique proves to be the most advantageous in detecting the virus because it has a higher sensitivity compared to the others. Conclusion: the PCR technique has high sensitivity (90-100\%) and presents 92.8 to $100 \%$ specificity, being the gold standard for the HPV DNA detection in cytology samples of uterus cervix cancer. Thus, the data obtained show that the PCR technique used for HPV screening is considered the gold standard, having greater sensitivity, specificity and speed of analysis, and should be the method of choice for the efficient diagnosis of HPV.

Keywords: Human papillomavirus (HPV). PCR. Real Time PCR. Uterine cancer. Cervical intraepithelial neoplasia.
\end{abstract}

\section{INTRODUÇÃO}

O câncer do colo do útero é o terceiro tipo de câncer mais comum sendo responsável pelo óbito de 265 mil mulheres por ano, com uma incidência de aproximadamente 530 mil casos novos no mundo, anualmente (INSTITUTO NACIONAL DE CÂNCER, 2015), e está asso-

Correspondente/Corresponding: *Carlos Maurício Cardeal Mendes Instituto de Ciências da Saúde, Universidade Federal da Bahia - End: Av. Reitor Miguel Calmon S/N - Vale do Canela Salvador-BA, Cep: 40110100 - Tel: (71) 99974-9504 - E-mail: mcardeal@ufba.br ciado ao papilomavírus humano (HPV). No Brasil, já em 2009, apresentava cerca de 40 mil novos casos por ano (RODRIGUES et al., 2009).

O papilomavírus humano (HPV) é um vírus pertencente à família Papillomaviridae, não envelopado, de forma icosaédrica, com ácido nucleico constituído de DNA de fita dupla circular com 7.900 pares de base, capsídeo com diâmetro de $55 \mathrm{~nm}$ e seu peso molecular é de $5,2 x$ 106 daltons (FEDERAÇÃO BRASILEIRA DAS SOCIEDADES DE GINECOLOGIA E OBSTETRÍCIA, 2002). 
O HPV infecta células epiteliais e causa lesões na pele ou nas mucosas. As lesões se manifestam como verruga comum e verruga genital ou condiloma, conhecida como "crista de galo". Possuem crescimento limitado e frequentemente regridem de forma espontânea (BROWN; FIFE, 1990).

Existem 14 tipos identificados como de alto risco (HPV tipos 16, 18, 31, 33, 35, 39, 45, 51, 52, 56, 58, 59, 66 e 68) que têm probabilidade maior de persistir e estarem associados a lesões pré-cancerígenas. O HPV de tipos $16 \mathrm{e}$ 18 causam a maioria dos casos de câncer de colo do útero em todo mundo (cerca de 70\%) (INSTITUTO NACIONAL DE CÂNCER, 2018).

O diagnóstico da infecção pelo HPV é feito através do exame de Papanicoloau, inspeção com ácido acético a 5\% e colposcopia, que não detecta o vírus, mas as alterações causadas por ele nas células; a biópsia, que fornece o diagnóstico histológico;

o diagnóstico por testes de hibridizações, tais como: teste de hibridização molecular, que é a técnica mais sensível (95-100\%) de deteç̧ão da infecção; a hibridização in situ (ISH), que detecta a presença do material genético do agente (DNA ou RNA) diretamente em cortes histológicos de tecidos; a técnica da captura híbrida, que utiliza sondas de RNA e tem a capacidade de detectar 18 dos aproximadamente 30 tipos de HPV que normalmente infectam o trato anogenital (JORDÃO et al., 2003); o microarray (microarranjos), técnica de hibridização que permite a investigação da expressão gênica, analisando vários genes ao mesmo tempo (NOVAES, L. C. G.; NOVAES, M. R. C. G.; SIMÕES-BARBOSA, 2006). A Restriction Fragment Lenght Polymorphism (PCR-RFLP) usa enzimas de restrição para a genotipagem viral. Na PCR-RFLP, o DNA é amplificado por uma PCR convencional, seguida de um processo de ação enzimática, capaz de reconhecer sítios de restrição específicos e clivados (cada indivíduo possui alterações ao longo do seu material genético) (RODRIGUES et al., 2009). A técnica da PCR permite a detecção, por amplificação, de qualquer fragmento de DNA (ou indiretamente RNA), cuja sequência seja conhecida (LIMA JUNIOR et al., 2011). Tem sido utilizada principalmente em pesquisas como um padrão ouro para comprovar ou não a existência do DNA do HPV (NONNENMACHER et al., 2002).

\section{OBJETIVO}

Descrever a evolução da PCR (reação em cadeia da polimerase) e sua contribuição no diagnóstico do papilomavírus humano (HPV).

\section{METODOLOGIA}

O estudo se caracteriza por uma revisão de literatura, realizada pela recuperação de artigos publicados em revistas científicas e elaborados com metodologia de referência, nos últimos cinco anos, disponíveis nas seguintes bases de dados: Science Direct; Scientific Eletronic Library Online (SciELO); Pubmed; Instituto Nacional do Câncer (INCA) e Ministério da Saúde (MS) do Brasil. Para identificar as publicações, foram utilizados os descritores: Papilomavírus humano; HPV; PCR; captura híbrida; CH. Foram selecionados artigos nos idiomas português e inglês.

\section{RESULTADOS E DISCUSSÕES}

Ao longo do século XX, a Biologia Molecular desenvolveu-se graças ao descobrimento da estrutura do DNA (1953), das técnicas de RNA recombinante (1970) e de novas técnicas e equipamentos (1995) que automatizaram o processo de sequenciamento do genoma de organismos vivos (OSADA; COSTA, 2006). Nos anos de 1980, a técnica de PCR foi descrita por Kary Mullis, rendendo-lhe o prêmio Nobel de Química em 1993 (ROSELINO, 2008). Esse prêmio foi recebido em conjunto com o canadense Michael Smith (1932). Mullis recebeu o prêmio por sua invenção da reação em cadeia da polimerase (PCR) e Smith desenvolveu um procedimento conhecido como mutagênese sítio dirigida e aplicou-o ao estudo de proteínas. $O$ avanço nessa técnica de Smith seria A PCR-RFLP (restriction fragment lenght polymorphism), ou seja, a identificação de polimorfismos de nucleotídeos (modificação genética), que inclusive pode ser feita por análise da curva de dissociação ou curva de melting (high resolution melting (HRM), cuja análise é obtida do produto amplificado amplicon, que é realizada automaticamente após a termociclagem por PCR, em tempo real, para deteç̧ão de mutações na sequência alvo (RODRIGUES et al., 2009). A partir daí foram desenvolvidas variações da técnica que têm permitido avanços consideráveis na Biologia Molecular e particularmente na detecção do HPV. É também uma ferramenta importante no sequenciamento de genes. Nos experimentos iniciais de PCR, utilizou-se a enzima de DNA polimerase de E. Coli, cuja temperatura de polimerização é de $37^{\circ} \mathrm{C}$, sendo necessária ser adicionada manualmente a cada ciclo de amplificação; porém, ela era destruída toda vez que a temperatura se elevava para $95^{\circ} \mathrm{C}$ para promover a desnaturação do DNA molde. Mullis descreveu sua técnica pela primeira vez na edição de 20 de dezembro de 1985 da revista Science e recebeu uma patente em 1987(SHAMPO; KYLE, 2002).

A grande difusão da PCR somente foi possível após a identificação de uma enzima polimerase de DNA resistente ao calor (Taq - Thermophilis aquatics), em 1986, o que possibilitou a simplificação da técnica, que dispensava a adição de mais DNA polimerase a cada ciclo (cerca de 30 ciclos cada um, com duração de apenas alguns minutos, produzia mais de 1 bilhão de cópias da sequência original de DNA), pois a Taq suporta temperaturas acima de $100^{\circ} \mathrm{C}$ (CARMO; FIORINI, 2007).

Segundo Rodrigues et al. (2009), um avanço importante na técnica de PCR foi o desenvolvimento de metodologias que possibilitaram o acompanhamento da amplificação do DNA em todos os ciclos ( inclusive com aumento na quantidade de 30 ciclos iniciais para 40 ciclos) e não somente em seu final (PCR convencional). PCR é a técnica mais sensível que existe atualmente e permite a 
deteç̧ão de 10 a 100 moléculas de DNA viral por amostra, para definir os genótipos associados em casos de infecções múltiplas, devido à produção de padrões de restrição confusos (AEDO et al., 2007).

Com a patente da PCR adquirida por parte da Perkin, desenvolve-se a automação para controle e flexibilização da temperatura, o que permite alternar o aquecimento e o resfriamento da proteína: é quando surge o Termociclador. O primeiro teste diagnóstico desenvolvido para HIV foi criado em 1992, eliminando o problema da janela imunológica estabelecida pelo vírus. Com o aprimoramento da técnica, após uma década, em 2003, surge a técnica PCR em Tempo Real ou QPCR, na qual se utiliza, além dos primers (iniciadores de amplificação), as sondas marcadas, possibilitando a quantificação do alvo em estudo.

O desenvolvimento da técnica de amplificação de segmentos de DNA, utilizando a PCR, ampliou perspectivas em várias áreas do conhecimento.

Atualmente, existem as seguintes técnicas de genotipagem para HPV: Teste de Hibridização Molecular; Hibridização In Situ (ISH); Captura Híbrida; PCR Convencional; PCR - RFLP; Nested PCR; PCR em Tempo Real; Multiplex $P C R$, Microarranjos, dentre outras, cada uma delas apresentando suas vantagens e desvantagens (RODRIGUES et al., 2009).

A sensibilidade e a especificidade das diversas técnicas de detecção do HPV disponíveis variam amplamente. A hibridização in situ (ISH) é considerada de baixa sensibilidade, devido a apenas detectar o vírus quando está presente em mais de 10 cópias do DNA viral por célula; os considerados de moderada sensibilidade (Southern blot, dot blot e hibridização dot reversa), por só detectarem o vírus quando de 1 a 10 cópias do DNA viral estiverem presentes e os de alta sensibilidade (PCR), por detectarem o vírus quando menos de uma cópia do DNA viral estiver presente (WOLSCHICK et. al., 2007).

A hibridização molecular é considerada como padrão de análise do genoma do HPV e requer fragmentos de DNA de comprimento total, além de informações adicionais importantes, como integração viral e subtipagem, porém, são procedimentos que consomem muito tempo e dinheiro. Quando se aumenta muito essa sensibilidade, principalmente na análise de lesões de baixo grau, pode haver reação cruzada, diminuindo a acurácia do método, devido à grande reação cruzada entre as sondas (WOLSCHICK et al., 2007).

A captura híbrida é uma reação de amplificação de sinal e associa métodos de hibridização molecular e antígenos monoclonais. Detecta com grande sensibilidade e especificidade o DNA/HPV em amostra de escovado ou biópsia do trato genital inferior (alto e baixo riscos oncogênicos) (SOLOMON et al., 2001).

A PCR convencional apresenta a vantagem do grande potencial para a detecção de níveis muito baixos de carga viral em células e tecidos e identificação de um grande número de tipos de HPV. Como desvantagem, pode ocorrer falha de amplificação por ineficiência de primers ou decorrente de um erro de extração de DNA (TAVARES et al., 2007).

A utilização da PCR convencional junto a polimorfismos de comprimentos dos fragmentos de restrição (RFLP) possibilita a detecção de cerca de 40 tipos de HPV; tal técnica faz uso de enzimas de restrição para genotipagem viral. A PCR RLFP apresenta menor sensibilidade quando a amostra está infectada por múltiplos tipos de HPV; e não identifica todos os tipos de HPV de alto risco. A distinção total de mais de 40 tipos de HPV também pode ser detectada por hibridização dot blot, aplicando múltiplas sondas tipo específicas (KANESHIMA et al., 2001).

O microarray (microarranjos), também conhecido como biochip, é frequentemente utilizado na análise de expressão gênica e análise de genoma funcional. Nessa técnica, as sequências de sondas ficam fixas em uma lâmina (in vitro) de forma organizada e têm a capacidade de se hibridizar com a amostra, devido ao princípio da complementaridade ou pela semelhança na sequência ( $\mathrm{CHOI}$ et al., 2005). Na detecção do HPV, o biochip tem a capacidade de determinar a presença de 24 tipos de HPV; destes, 9 são considerados de baixo risco oncogênico e 15 , de alto risco (GUINDALNI; TUFIK, 2007).

A Nested PCR possui alta sensibilidade e maior especificidade do que as outras técnicas, sendo $38 \%$ mais específica que a PCR convencional. Esta técnica tem como princípio a amplificação de uma sequência presente em um fragmento previamente amplificado, diferentemente da PCR convencional, sendo utilizados dois conjuntos de primers diferentes. Constitui-se de duas fases de amplificação: inicialmente, faz uso do par de primers MY09/MY11, que se anela na região $L 1$, produzindo um fragmento de $450 \mathrm{pb}$, ocorrendo uma reamplificação na região alvo, pois é considerada a mais conservada do vírus HPV.

São realizados 40 ciclos, nos quais, ocorrem as etapas: desnaturação, anelamento e extensão que identificam o DNA viral em amostras com infecções múltiplas (CARVALHO et al., 2010). Após a primeira amplificação, o produto obtido dessa etapa é submetida a uma nova PCR, entretanto, esta se utiliza do par de primers GP5+/GP6+ que gera um fragmento de $150 \mathrm{pb}$, a partir do produto do primeira corrida , aumentando, assim, o grau de especificidade da técnica (SRIAUNKGUL et al., 2008). O produto final é finalizado com uma técnica de eletroforese em gel de poliacrilamida. Pela necessidade da técnica Nested ocorrer em duas etapas de amplificação, torna-se demorada e em desvantagem em relação ao PCR TR (CARVALHO et al., 2010).

A Multiplex PCR é uma técnica que permite a amplificação de vários loci em uma única reação (uso de mais um par de primers), além de promover a busca de variações no mesmo vírus ou no diagnóstico de doenças que podem ser causados por diferentes patógenos (CARMO; FIORINI, 2007).

A PCR RT (reverse transcriptase) tem como objetivo a conversão da fita simples de m RNA em DNA complementar (c DNA), utilizando a enzima transcriptase reversa. Através da transcrição reversa, realizada pela 
ação da enzima transcriptase reversa, uma cópia de DNA complementar (c DNA) é sintetizada a partir da RNA viral (genoma ou produto intermediário do processo de replicação). Essa nova molécula sintetizada será usada como molde para a reação de PCR convencional (BROCCOLO; COCUZZA, 2007).

A PCR-RT (real time) é uma técnica inovadora, capaz de promover a quantificação acurada e o monitoramento em tempo real do produto amplificado; possui as mesmas três etapas da PCR convencional, diferenciando-se pela quantificação de expressão viral em tempo real. Essa técnica tem a capacidade de detectar e quantificar a amplificação do produto à medida que vai sendo sintetizado. Utiliza, além dos primers, uma sonda marcada com um fluorocromo. A sonda é complementar a uma região interna do produto e é marcada com uma substância fluorogênica. Essa multiplicação ocorre a partir da separação das fitas de DNA (desnaturação) com posterior ligação dos primers à molécula de DNA (anelamento) e ação da enzima DNA polimerase (extensão), que alonga a molécula em formação, utilizando-se os desoxinucleotídeos livres na reação (XAVIER; OLIVEIRA; SEVERO, 2009). A PCR - (Real Time) possui a vantagem em relação às outras técnicas moleculares, por detectar diversos tipos virais de alto risco, determinar o tipo viral específico, revelar a presença do vírus no início da infecção, menor índice de contaminação da amostra, porém é necessário alto custo em equipamento para análise da amostra (software). A PCR-TR tem a vantagem sobre a PCRc em termos de velocidade: 20 à $30 \mathrm{~min}$. Devido à alta sensibilidade e à rapidez (sendo 10\% mais sensível), os métodos de PCR poderiam ser usados para a triagem de HPV em amostras ectocervicais (RODRIGUES et al., 2009).

No que diz respeito ao HPV, estudo realizado por Nonnenmacher et al. em 2002, utilizando PCR, encontrou uma frequência de $16 \%$ de DNA do HPV em mulheres.

Lonky et al. em 2003, demonstraram que a captura híbrida foi negativa em $25 \%$ dos casos com PCR positivo para HPV de alto risco, em pacientes com ASCUS, limitando sua escolha para o diagnóstico precoce.

Segundo Wolschick et al. (2007), a PCR é considerada a técnica padrão ouro com maior sensibilidade, especificidade e velocidade de análise, devendo ser o método de escolha para o diagnóstico do HPV.

Ainda em 2007, Nomelini et al. desenvolveram uma pesquisa, na qual pacientes selecionados que apresentaram anormalidades na colposcopia foram testados pelas técnicas de PCR e captura híbrida. A sensibilidade do PCR e da captura híbrida na detecção de neoplasia intraepitelial cervical (NIC), no estudo referido, foi de $83,33 \%$ e $66,67 \%$, respectivamente. $\mathrm{O}$ valor preditivo negativo no diagnóstico de NIC II e III do PCR e captura híbrida foi de $100 \%$ e 94,74\%, respectivamente.

No que se refere ao risco de desenvolvimento de câncer de colo uterino em mulheres com infecção por HPV, estudo de Van Dergraaf et al. (2002) demonstrou ser 19 vezes maior do que em mulheres sem infecção pelo HPV e que mulheres com os tipos oncogênicos 18, 31 ou 33 têm um risco maior do que 50 vezes, comparado ao daquelas não infectadas por esses genes e, se considerado o HPV 16, esse risco teve aumento de mais de 100 vezes.

Evander et al. (1992), ao compararem a PCR utilizando os pares de oligonucleotídeos MY09/MY11 e GP5/GP6 e a nPCR com MY/GP, com a utilização dos oligonucleotídeos MY09/MY11 na PCR o DNA do HPV, detectaram 26,3\% dos casos de citologia exfoliativa com alterações patológicas. Empregando-se a n PCR esta capacidade de detecção aumentou para $84,2 \%$ nestes espécimes.

Husnjak et al. (2000), ao utilizarem amostras de citologia cervical e compararem os métodos da PCR com os oligonucleotídeos MY09/MY11 e Nested com MY09/MY11, seguidos por GP5/GP6, encontraram um aumento de $38,8 \%$ na taxa de positividade para o DNA do HPV; quando comparam com PCR e n PCR, encontraram valores inferiores aos dos experimentos realizados por Evander et al. (1992).

Já Demathe et al. (2010), ao compararem a utilização de PCR simples e Nested-PCR na deteç̧ão de HPV em carcinoma epidermoide de lábio, observaram um aumento de mais de seis vezes no número de casos de HPV, ao utilizar o método de $\mathrm{nPCR}$.

Michelli et al. (2011), em pesquisa cujo objetivo era comparar três métodos de detecção do DNA do HPV (PCR, utilizando primers da região L1; PCR utilizando primers da região E6/E7; e captura híbrida), em 100 amostras cervicais de mulheres sexualmente ativas, observaram que $40 \%$ das mulheres foram positivas em, pelo menos, umas das técnicas diagnósticas testadas.

Verificou-se que $12 \%$ das mulheres apresentaram resultados positivos na captura híbrida, 26\% na PCR L1 e $26 \%$ na PCR E6/E7. Com relação à técnica de PCR, $16 \%$ das mulheres obtiveram resultados positivos em ambos os métodos. Apenas $4 \%$ das mulheres tiveram resultados positivos nos três métodos.

Figura 1 - Representação esquemática do genoma do HPV-16 $L$ (Late) - genes que se expressam tardiamente no ciclo vital do vírus. $E$ (Early) - genes que se expressam precocemente no ciclo vital do vírus. LCR (Long Controll Region) - gene que fica entre o final da L1 e o início de E6.

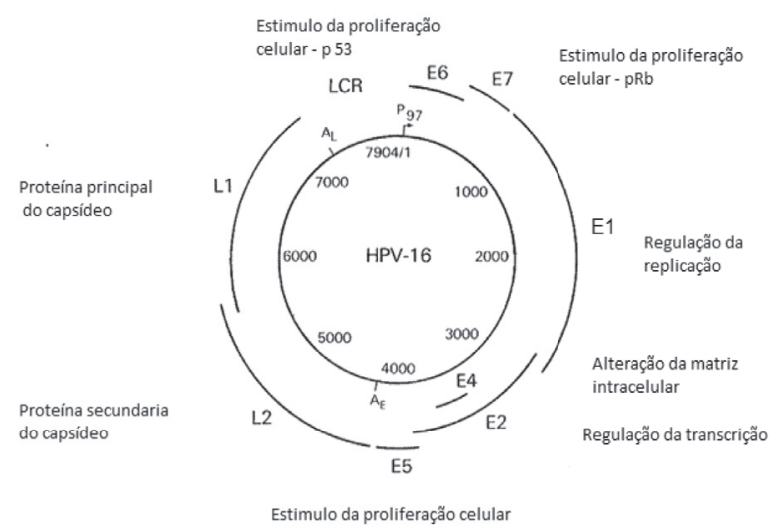

Fonte: Adaptado de Bringhenti et al. (2010). 
A PCR específica tem como objetivo a genotipagem do vírus em análise; os primers usados são complementares a regiões com variação de nucleotídeos que determinam o genótipo do vírus; esses primers são chamados de específicos e, no HPV, os alvos são os genes E6 e E7. O HPV está arranjado estruturalmente em: genes precoces (E1 - E7), caracterizados pela formação de proteínas não estruturais, necessárias para a replicação viral; genes tardios (L1 - L2), caracterizados pela formação de proteínas estruturais do capsídio, para montagem do virion; e a região reguladora de controle longo (LCR), que está relacionada com os fatores de replicação e transcrição viral. Esse método permite selecionar iniciadores específicos de regiões únicas, presentes nos genes E6 e E7 de cada subtipo do HPV, ou podem ser utilizados iniciadores para regiões conservadas ou comuns do genoma do vírus, como a L1 (WOLSCHICK et al., 2007). Esses genes, com potencial oncogênico, complexam-se respectivamente com a proteínas celulares denominadas p53 e pRb, levando à inativação e consequentemente ao descontrole do ciclo celular (WENTZENSEN; VON KNEBEL DOEBERITZ, 2007).

Os métodos moleculares que evidenciam a molécula do DNA (PCR) na amostra do paciente vêm ganhando espaço no escopo do diagnóstico laboratorial e, apesar da desvantagem do alto custo, da necessidade de equipe técnica especializada e de infraestrutura adequada, disponibilizam um melhor desempenho diagnóstico em relação os métodos imunológicos, nos quais se identifica a doença por meio da quantificação dos anticorpos contra os patógenos. Das técnicas abordadas nesta revisão, a metodologia Nested PCR se sobressai no diagnóstico precoce dos genes oncogênicos de alto grau, no caso de infecção persistente do HPV, aumentando a chance de cura através do tratamento das lesões precursoras, o que reduz a progressão do câncer do colo do útero. Esses exames de biologia molecular identificam principalmente os casos de infecção latente por HPV, presente em 30\% das mulheres sexualmente ativas (LUU et al., 2013). Todas essas lesões são passíveis de cura em até $100 \%$ dos casos, quando tratadas precocemente. Se o rastreamento for realizado de forma correta, ele apresenta uma cobertura de $80 \%$ para o câncer e, se as lesões iniciais forem tratadas, reduze-se o aparecimento de câncer cervical em até $90 \%$ (WOLSCHICK et al., 2007).

\section{CONCLUSÃO}

O diagnóstico precoce do HPV é fundamental para o controle do câncer de colo de útero. Nesta revisão de literatura, visando oferecer um método que auxilie o diagnóstico diferencial ou mesmo indicador da transformação neoplásica, os dados obtidos permitem constatar que a técnica PCR, utilizada para o rastreamento do HPV, tem alta sensibilidade (90-100\%) e apresenta 92,8 a $100 \%$ de especificidade, sendo o método mais utilizado para a detecção de DNA do HPV. Concordância dos resultados prévios da citologia oncótica (Papanicolau), método de screening (triagem) com os resultados dos testes moleculares para HPV, que ostentam uma maior acurácia, propiciarão uma rápida intervenção diagnóstica, minimizando os índices de morbidade e mortalidade, além de identificar e priorizar mulheres com elevado risco de desenvolvimento de câncer de colo do útero, sendo uma indispensável ferramenta como medida de prevenção e controle da doença.

\section{REFERÊNCIAS}

AEDO, A. S. et al. Detección y tipificación de virus papiloma humano en lesiones preneoplásicas del cuello uterino mediante PCR-RFLP. Rev. Méd. Chile, Santiago, v. 135, n. 2, p. 167-173, 2007.

BRINGHENTI, M. E. Z. et al. Cervical cancer prevention: association of new techniques of molecular biology with the oncotic cytology in detection of human papillomavirus (HPV). DST J. Bras. Doenças Sex. Transm., Rio de Janeiro, v. 22, n.3, p. 135-140, 2010.

BROCCOLO, F.; COCUZZA, C. E. Automated extraction and quantification of oncogenic HPV genotypes from cervical samples by a real-time PCR-based system. J. Virol. Methods., v. 148, n. 1-2, p. 48-57, Nov 2007.

BROWN, D. R.; FIFE, K. H. Human papillomavirus infections of the genital tract. Med. Clin. North Am., Philadelphia, v. 74, n. 6, p. 1455-1485, 1990.

CARMO, E. F. S.; FIORINI, A. Principais técnicas moleculares para detecção do Papilomavírus humano. Saúde e Biologia, Maringá, v. 2, n. 1, p.29-31, jun. 2007.

CARVALHO, N. O. et al. Comparison of HPV genotyping by type-specific pcr and sequencing. Mem. Inst. Oswaldo Cruz, Rio de Janeiro, v. 105, n.1, p. 73-78, Feb. 2010. Disponível em: http://www. bioline.org.br/ pdf?oc10011. Acesso em: 12 July 2011.

CHOI, Y-D. et al. Detection of HPV genotypes in cervical lesions by the HPV DNA Chip and sequencing. Gynecol. Oncol., New York, v. 98, n.3, p. 369-375, Sept. 2005. Disponível em: http://www.sciencedirect.com/ science/article/pii/S0090825805003434. Acesso em: 10 Aug 2011.

DEMATHE, A. et al. Comparação entre dois métodos de detecção de DNA de Papilomavírus humano em carcinoma epidermoide de lábio. J. Bras. Patol. Med. Lab., Rio de Janeiro, v. 46, n. 2, p. 85-90, 2010.

EVANDER, M. et al. Comparison of a one-step and a two-step polymerase chain reaction with degenerate general primers in a population based study of human papillomavirus infection in young Swedish women. J. Clin. Microbiol., Washington, v. 30, n. 4, p. 987-992, 1992.

FEDERAÇÃO BRASILEIRA DAS SOCIEDADES DE GINECOLOGIA E OBSTETRÍCIA. Projeto Diretrizes: papilomavírus humano (HPV): diagnóstico e tratamento. São Paulo: Febrasgo, 2002. 19 p.

GUINDALNI, I. C.; TUFIK, S. Uso de microarrays na busca de perfis de expressão gênica - aplicação no estudo de fenótipos complexos. Rev. Bras. Psiquiat., São Paulo, v.29, n. 4, p.370-374, 2007. Disponível em: http://www.scielo.br/scielo.php?script=sci_art text\&pid =S1516-44462007000400014. Acesso em: 03 ago. 2011.

HUSNJAK, K. et al. Comparison of five different polymerase chain reaction methods for detection of human papillomavirus in cervical cell specimens. J. Virol. Methods, Amsterdam, v. 88, n. 2, p. 125-134, 2000.

INSTITUTO NACIONAL DE CÂNCER . Incidência de câncer no Brasil: estimativa 2018. Rio de Janeiro: INCA, 2018.

INSTITUTO NACIONAL DE CÂNCER. Brasil. Ministério da Saúde. Estimativa 2016: incidência do câncer no Brasil. Rio de Janeiro: INCA, 2015. 
126 p. Disponível em: santacasadermatoazulay.com.br/wp-ontent/ uploads/2017/06/estimativa-2016-v11.pdf. Acesso em: 20 dez. 2015.

JORDÃO, A. V. et al. Importância da aplicação de critérios morfológicos não clássicos para diagnóstico citológico de Papilomavírus humano. J. Bras. Patol. Med. Lab., Rio de Janeiro, v. 39, n. 1, p. 81-89, ago. 2003.

KANESHIMA, E. N. et al. Aplicação do método PCR-RFLP para tipagem de HPV em infecções cervicais de pacientes atendidas no Lepac, Universidade Estadual de Maringá. Acta Sci., Maringá, v. 23, n.3, p. 731-737, 2001.

LIMA JUNIOR, S. F. et al. Prevalência dos genótipos do Papilomavírus humano: comparação entre três métodos de detecção em pacientes de Pernambuco, Brasil. Rev. Bras. Ginecol. Obstet., Rio de Janeiro, v.33, n. 10, p. 315-320, 2011.

LONKY, N. M. et al. Triage of atypical squamous cells of undetermined significance with hybrid capture II: colposcopy and histologic human papillomavirus correlation. Obstet. Gynecol., Hagerstown, v. 101, n. 3, p. 481-489, 2003.

LUU, H. U. N. et al. Comparing the Performance of Hybrid Capture II and Polymerase Chain Reaction (PCR) for the identification of cervical dysplasia in the screening and diagnostic settings. Clin. Med. Insights Oncol., v. 7, p.247-255, set. 2013.

MICHELLI, E. et al. Comparative analysis of three methods for HPV DNA detection in cervical samples. Invest Clin., Granada, v. 52, n. 4, p. 344-357, 2011.

NOMELINI, R. S. et al. Utilization of human papillomavirus testing for cervical cancer prevention in a university hospital. Cad. Saúde Pública, Rio de Janeiro, v. 23, n. 6, p. 1309-1318, 2007.

NONNENMACHER, B. et al. Identificação do papilomavírus humano por biologia molecular em mulheres assintomáticas. Rev. Saúde Pública, São Paulo, v. 36, p. 95-100, 2002.

NOVAES, L. C. G.; NOVAES, M. R. C. G.; SIMÕES-BARBOSA, A. Diagnosis of human papillomatosis by polymerase chain reaction in cases of divergence between results of hybrid capture and papanicolaou cytology. Braz. J. Infect. Dis., Salvador, v. 10, n. 3, p. 169-172, 2006.

OSADA, N. M.; COSTA, M. C. A construção social de gênero na Biologia: preconceitos e obstáculos na biologia molecular. Cadernos Pagu, São Paulo, v. 27, p. 279-299, 2006.

RODRIGUES, A. D. et al. Comparação das técnicas de captura de híbridos e PCR para a detecção de HPV em amostras clínicas. J. Bras. Patol. Med. Lab., Rio de Janeiro, v. 45, n. 6, p. 457-462, dez. 2009.

ROSELINO, A. M. Biologia molecular aplicada às dermatoses tropicais. An. Bras. Dermatol., Rio de Janeiro, v. 83, n. 3, p. 187-203, 2008.

SHAMPO, M. A.; KYLE, R. A. Kary B. Mullis - Nobel laureate for procedure to replicate DNA. Mayo Clin. Proc., Rochester, v. 77, n.7, p. 606, 2002.

SOLOMON, D. et al. The 2001 Bethesda System: terminology for reporting results of cervical cytology. JAMA, Chicago, v. 287, n.16, p. 2114-2119, 2002.

SOLOMON, D. et al. Comparison of three management strategies for patients with atypical squamous cells of undetermined significance: baseline results from a randomized trial. J. Natl. Cancer Inst., Cary, v. 93, n. 4, p. 293-299, 2001.

SRIAUNKGUL, S. et al. HPV genotyping in cervical cancer in Northern Thailand adapting the linear array HPV assay for use on paraffin-embedded tissue. Gynecol. Oncol., New York, v. 108, n. 3, p.555-560, Mar. 2008.

TAVARES, S. B. N. et al. Controle de qualidade em citopatologia cervical. Rev. Bras. Cancerol., Rio de Janeiro, v. 53, n.3, p. 355-364, 2007. Disponível em: http://www.inca.gov.br/rbc/n_53/v03/pdf/revisao6.pdf. Acesso em: 15 ago. 2011.

VAN DERGRAAF, Y. et al. Human papillomavirus and the long-term risk of cervical neoplasia. Am. J. Epidemiol., Baltimore, v. 56, p. 158-164, 2002.

WENTZENSEN, N.; VON KNEBEL DOEBERITZ, M. Biomarkers in cervical cancer screening. Dis. Markers, Chichester, v. 23, n. 4, p.315-330, 2007.

WOLSCHICK, N. M. et al. Câncer do colo do útero: tecnologias emergentes no diagnóstico, tratamento e prevenção da doença. Rev. Bras. Anal. Clin., Rio de Janeiro, v. 39, n .2, p.123-129, 2007.

XAVIER, M. O; OLIVEIRA, F. M.; SEVERO, L. C. Diagnóstico laboratorial das micoses pulmonares. J. Bras. Pneumol., São Paulo, v. 35, n. 9, p. 907-919, 2009.

Submetido em: 07/11/2019

Aceito em: 30/11/2019 